\title{
NUEVA GENEALOGÍA DE SANTA TERESA
}

\section{(ARTÍGULO-RESEÑA)}

Aunque hace ya diez años que Narciso Alonso Cortés publicó una serie de importantes documentos relativos a la familia de Santa Teresa, es notable la poca atención que se les ha concedido, lo cual puede deberse al título poco explícito y significativo que el investigador vallisoletano escogió para esa publicación: "Pleitos de los Cepedas" 1 . Tres son los pleitos allí registrados, pero en la presente reseña vamos a ocuparnos casi exclusivamente del primero, que es el que atañe de manera directa a los antecedentes genealógicos de la Santa.

Este primer pleito fue incoado el 6 de agosto de $15^{19}$ ante el tribunal de la Real Chancillería de Valladolid por Alonso Sánchez de Cepeda y sus hermanos Pedro Sánchez de Cepeda, Ruy Sánchez de Cepeda y Francisco Alvarez de Cepeda, padre y tíos respectivamente de Santa Teresa, con el fin de acreditar su hidalguía ${ }^{2}$. Las autoridades municipales del concejo de Hortigosa, parroquia de Majalbálago, aldea cercana a Ávila, reclamaban a cada uno de ellos el pago de cien maravedís, como pecheros obligados al pago de contribución. Los pleiteantes se negaban a pagar pecho, pues pretendían "ser omes hijosdalgo de padre y de agüelo" (p. 87).

El Dr. Villarruel, fiscal de Sus Altezas, declaraba, en cambio, con fecha 23 de noviembre de 1519 , que eran hijos de pechero y que se llamaban Cepeda por abolengo de su madre; que el padre fue pechero y tenido por tal en Toledo, donde moró mucho tiempo, y que allí hizo cierta reconciliación y penitencia ante los señores inquisidores, por lo

1 N. Alonso Cortis, "Pleitos de los Cepedas", BAE, 25 (1946), 85-110. E1 profesor M. J. Benardete, del Brooklyn College de Nueva York, fue quien me llamó la atención acerca de estos documentos. Alonso Cortés, que los descubrió en el archivo de la Real Chancillería de Valladolid (Sala de los Hijosdalgo, legajo 45), copia íntegros los mís importantes, extracta otros, y añade algunos comentarios.

2 Alonso Cortís anota (p. 85) que este pleito se halla mencionado en el repertorio de Alfredo Basanta de la Riva, Archivo de la $R$. Chancilleria de Valladolid, Sala de los Hijosdalgo, Catálogo de todos sus pleitos, expedientes y probanzas, VaIladolid, 1920-1922, t. 3, p. 328, y que al mismo pleito hacen referencia los biógrafos de Santa Teresa; pero "como sin duda no han visto el proceso original..., sino solamente los testimonios de la ejecutoria conservados en los conventos de Osuna y de San José de Ávila, que, a lo que resulta, están incompletos, omiten muy importantes datos". Don Bernardino de Melgar publicó la parte que se conocía, a saber, las declaraciones favorables de dos testigos y la sentencia en que se acredita la hidalguia, cn el $B A H, 67(1915), 35^{8-366}$ y $381-382 .-$ En adelante, todas las citas de MELciAR se refieren, salvo indicación en contrario, a estudios publicados en este volumen 67 del $B A H$. 
cual se marchó de esa ciudad y vino a vivir en Ávila ${ }^{3}$ "en hábito" de mercader, como antes lo era, pues en Toledo "puso e tuvo tienda de mercadería mucho tienpo" (p. 87). También la comunidad de Ávila alegaba que los hijos de 'Juan Sánchez de Toledo, nacidos en Toledo, "son conversos e descienden de linaje de judíos por parte de su padre e abuelo" (p. 91). Es de notar que ni el fiscal ni la comunidad mencionan miembro alguno del lado materno.

El tribunal solicitó información de las autoridades de Toledo, y los inquisidores de esta ciudad, licenciados Sancho Vélez y Juan de Mendoza, citaron en audiencia a dos testigos. El primero, Pedro de Cepeda, mercader, compareció el 17 de julio de 1520 y depuso, bajo juramento, que conoció a Joan Sánchez de Toledo, difunto, casado con Inés de Cepeda, hermana del declarante; que era mercader y que fue reconciliado en tiempo de gracia; y que conoció asimismo a su hijo, Fernando de Santa Catalina, el cual marchó mozo a Salamanca a estudiar, y allí, siendo bachiller, se casó, se avecindó y falleció, alrededor de 1508 , sin ser reconciliado (pp. 88-89). El segundo testigo, Enrique Hamusco, nacido alrededor de 1468, "maestro en santa teología, racionero en la Santa Iglesia desta dicha cibdad de Toledo", prestó análoga declaración, añadiendo que también conoció al padre de Joan Sánchez de Toledo, Alonso Sánchez, mercader, ya difunto, y al hijo de aquél, que "era bachiller en leyes y cánones..., el qual casó en Salamanca con doña Martina de Miranda..., y quel dicho Joan Sánchez era hermano de la madre deste testigo" (p. 89).

Finalmente, el escribano y notario público por la autoridad apostólica y real y notario del secreto en el Santo Oficio de la Inquisición de Toledo, dio fe en 19 de julio de $15^{20}$ de "que parece y consta por los libros e registros deste Sancto Oficio cómo en 22 días del mes de junio de ${ }^{4} 85$ Johan de Toledo, mercader, hijo de Alonso Sánchez, vezinos de Toledo a la colación de Santa Leocadia, dio, presentó e juró ante los señores ynquisidores... una confesión", y que en el libro "yntitulado Repertorio de las personas reconciliadas" ${ }_{4}$ está inscrito el nombre de Joan de Toledo, y no el de Fernando de Santa Catalina (p. 9o).

Continuadas las actuaciones del pleito en Valladolid, se procedió a tomar declaración a los testigos de cargo y de descargo, los primeros presentados por el fiscal y la comunidad de Avila, y los segundos por Alonso Sánchez de Cepeda y sus hermanos, en total dieciocho testigos. Sus declaraciones pueden resumirse del siguiente modo:

Juan Sánchez de Toledo, ya asentado en Avila por 1491 o 1494, mercader, traficante en efectos de iglesias, pan y otras cosas, era confeso y reconciliado (p. 93); "seyendo ynquisidores en Toledo el licenciado Costana e don Busto Ramírez de Rybera, vio [el testigo Juan González de las Piñuelas] que los dichos ynquisidores en penitencia echaron al dicho Juan Sánchez de Toledo un sanbenitillo con sus cruces e lo

3 Ahora se puede contestar documentalmente a la pregunta que hacía Mrtgar, p. 379: “¿Por qué abandonaron Toledo para trasladar a la ciudad de Avila su residencia definitiva hacia el año de 1504 ?"

${ }^{4}$ Los Reyes Católicos mandaron que todos los judios conversos se reconciliaran con la Inquisición en un plazo que vencería a fines de 1484 (Joseph JACOBS, en The Jew'ish Encyclopedia, New York and London, t. 11, 1905, p. 500b). 
traía públicamente los viernes en la procesión de reconciliados que andaban de penitencia syete viernes, de yglesia en yglesia" (p. 95); poseía buena hacienda, y era escudero con sus correspondientes caballo y armas; falleció en Ávila alrededor de 1508. Lope Fernández Gallego, hidalgo, de 64 años, "conosció a Juan Sánchez de Toledo... mercader... e oyó dezir públicamente en la dicha cibdad [de Ávila]... que era confeso e reconciliado... e que a... sus hijos... ha visto e ve que son honbres de bien... pero que sabe que son habidos e tenidos por confesos de parte de dicho su padre". "Sabe que [padre e hijo] se vinieron a vivir a... Ávila, de la cibdad de Toledo, de donde son naturales" (p. 93). Sus hijos son arrendadores y mercaderes. Casaron, testifica otro, con parientas de algunos regidores o concejales de Ávila, "onbres hijosdalgo"; a causa de ello fueron favorecidos por dichos regidores, y mediante sus influencias dejaron de pechar y se convirtieron en hidalgos (p. 94) ${ }^{5}$. Otros testigos los conocen también como hidalgos. Uno de ellos vio a Alonso Sánchez de Cepeda (padre de Santa Teresa) marchar a servir a Su Alteza en la guerra de Navarra (1512), cuando el Rey Católico dirigió cédulas a los caballeros de Ávila, entre ellos a los Sánchez de Cepeda, tenidos por hidalgos, y lo vio montado en "muy buen caballo... con armas como caballero bien arreado de guerra e de atavío", con mula y acémila (pp. 99-100). Años más adelante, la niña Teresa escucharía de labios de su padre el relato de los arriesgados lances en que habría tomado parte durante aquella guerra, y se lo representaría a caballo, armado de todas armas, y lo admiraría, en su imaginación infantil, cual si fuera en realidad uno de los caballeros andantes, héroes de los libros de caballerías que tanto gustaba de leer.

Concluso el pleito de hidalguía, los alcaldes de la Chancillería dictaron sentencia favorable a los litigantes el 16 de noviembre de 1520 . Apelaron contra ella el fiscal y la comunidad de Ávila, pero los oidores confirmaron el fallo de los alcaldes, declarándolo definitivo en 26 de agosto de 1522, fecha en la cual quedó reconocida la hidalguía de los hermanos Cepeda.

No cabe duda de que se trataba de una familia acaudalada de conversos. Los declarantes están contestes en ello. Desde el bisabuelo, mercader que poseía casas y viñas en Toledo (p. 98), y el abuelo, que tenía "una tienda rica de paños y sedas" en la calle del Andrino o Endrino, en Ávila, en la que despachaban dos mancebos o dependientes (p. 92), hasta los hijos, que eran, como el padre, arrendadores o recaudadores de rentas, "así las tercias reales" (el tercio de los diezmos que correspondía a la corona), como "los votos ${ }^{6}$ e otras rentas" (p. 94), y a quienes pertenecían heredades en algunas de las aldeas de los alrededores de Âvila, todos estaban bien acomodados. Sólo un hijo no se dedicó

5 M. Kayserling, en The Jewish Encyclopedia, tomo cit., p. 498a, afirma que, por su talento y riqueza y por medio de matrimonios con hijas de familias nobles, los conversos lograron considerable influencia en España.

- Del voto de Santiago. Acuerdo de los obispos y abades que cstablecieron "que de quantas yugadas de bueys oviesse en tierra de cristianos, que diessen de cada una sennas medidas de pan, como por primicia, a los clérigos que sirviessen a la eglesia de sant Yagüe; et otrossí del vino de cada moyo" (Primera crónica general, cap. 63o, ed. Menéndez Pidal, 1906, p. $3^{61 a}$ ). 
al comercio y los negocios, Fernando de Santa Catalina, el bachiller. Hombres "muy limpios, honrados y ricos" los describe Gómez Daza, hidalgo de 61 años, "con sus caballos muy buenos e sus personas muy bien ataviadas". Se portan y han portado "como hidalgos e aun como caballeros, e como tales se han tratado con hijos de muy buenos hidalgos e parientes de caballeros de los principales de la cibdad de Ávila". "De buena conversación", agrega otro declarante (p. 94).

La familia mantenía buenas relaciones con altos dignatarios eclesiásticos, y aun contaba con parientes clérigos. Juan Sánchez de Toledo, abuelo de la Santa, tenía, como hemos visto, un sobrino, hijo de su hermana, el nombrado Enrique Hamusco, que era canónigo de la catedral de Toledo. Un testigo refiere que Juan Sánchez, no obstante tener residencia en Ávila, "vivía en Salamanca con el arzobispo de Santiago" (p. 92). Otro testigo manifiesta que Francisco Álvarez de Cepeda, hijo del anterior, "vivió un tiempo con el obispo de Plasencia" (p. 98). Quizá fuesen sus administradores o tesoreros ${ }^{\tau}$. El primer testigo agrega que Juan llegó a ser "secretario del rey don Enrique" (p. 92). Se sabe que Enrique IV de Castilla era amigo de los judíos ${ }^{8}$.

Con los nuevos documentos descubiertos por Alonso Cortés, podemos ahora rehacer, rectificar y adicionar el árbol genealógico de Santa Teresa. Hemos tenido también en cuenta los datos que se hallan en las biografías más importantes de la Santa, haciendo caso omiso de muchas otras que se multiplicaron, copiándose las unas a las otras. Hemos utilizado, pues, sólo las siguientes: la del P. Ribera, su primer biógrafo; la de fray Luis de León, primer editor de las obras de la Santa; la del P. Jerónimo Gracián, rareza bibliográfica que no hemos visto citada; la del P. Julián de Ávila, coetáneo asimismo; la de Vicente de la Fuente, con nuevos documentos; la del P. Mir, que utiliza el epistolario de la Santa; la del P. Silverio de Santa Teresa, la más completa y autorizada de todas, y la biografía de Walsh, resumen de las numerosas vidas anteriores, lo que explica su mérito y utilidad $^{9}$. Recientemente

7 "Cuando se estudian sus genealogías [de los conversos] en los procesos de Inquisición, se queda uno asombrado al ver a tantos miembros de esas familias... al servicio de los grandes, especialmente en calidad de administradores, mayordomos o secretarios" (M. Batalllon, Erasmo y España, trad. A. Alatorre, México, 1950, t. 1, p. 212 ).

s Kayserling, loc. cit., p. $499 b$, explica cómo la posición de los judíos en España fue bastante favorable en la segunda mitad del siglo $\mathrm{xv}$, durante los reinados de Enrique IV de Castilla (1454-74) y de Juan II de Aragón (1458-79). Acaudalados conversos ocuparon cargos prominentes en ambas cortes. Enrique IV nombró a Diego Arias Dívila contador mayor del reino y empleó como recaudadores a parientes de Dávila, cristianos nuevos, así como a otros judíos.-Véase también Américo Ciastro, España en su historia, Buenos Aires, 1948, pp. 94 y 513-514.

- Francisco de Ribrra, Vida de Teresa de Jesús, Salamanca, 1590 [escrita en ${ }_{15}^{88}$ ], nueva ed. con notas del P. Jerónimo Gracián, e introd. y adiciones por el P. Jaime Pons, Barcelona, 1908.-Los libros de la Madre Teresa de Jesús (con su vida escrita por ella misma y adicionada por fray LuIS dE Liós), Salamanca, 1588. (La $1^{\text {a }}$ ed., muy rara, es de Évora, 1583 ; la H. S. A. posee úna ed. de Madrid, 1597, 2 vols. en uno: la Vida con las Relaciones añadidas, ej. raro; Narciso Martínez Izquierdo descubrió un ms. de fray Lurs de LEón, De la vida, muerte, virtudes y milagros de la Santa Madre Teresa de Jesús, y lo publicó en la Rev. Agustiniana, enero-marzo 1883).-Fray Jirónimo Gracián, Declamación en que se trata de la perfecta vida y virtudes heroycas de la B. Madre Theresa de Jesús, y de las fundacio- 
ha visto la luz una nueva biografía por el P. Efrén, que no hemos logrado ver, pero sí el librito en que el $\mathbf{P}$. Ferreol Hernández refuta la novedad que parece ofrecernos el P. Efrén, de cómo Santa Teresa no nació en Âvila, sino en Gotarrendura ${ }^{10}$. El P. Ferreol, con prueba documental, demuestra de manera convincente y definitiva que Teresa de Jesús vio la luz primera en la ciudad de Ávila, según lo habían venido consignando todos los biógrafos desde los coetáneos de la Santa ${ }^{11}$, y se afana en deshacer "otros muchos errores históricos [del P. Efrén], nacidos o de falta de espíritu crítico o de investigación"12. Rebuscando el autor en el Archivo de Protocolos, que se halla en el Archivo Histórico Provincial de Ávila, ha realizado numerosos descubrimientos de escrituras de venta, compra, arrendamiento, otorgamiento de poderes, etc., del padre de la Santa. Por último, cree haber encontrado el nombre de un nuevo hermano de Teresa (pp. 178-192), el que faltaba para completar el total de doce, número atestiguado por la propia declaración de la Santa en el cap. 1 de su Vida, donde dice: "Éramos tres hermanas y nueve hermanos". El nombre, en el cual ninguno de sus biógrafos había reparado, es Juan de Ahumada ${ }^{13}$. Hemos consultado, además, los documentos descubiertos y transcritos por Vicente de la Fuente (loc. cit.), por Serrano y Sanz (loc. cit.), por el P. Fidel Fita, por B. de

nes de sus monasterios, Bruselas, 1611 (ej. en la H. S. A., acaso único)--Julián dE Ávil. Vida de Santa Teresa de Jesús (ms. terminado en 1604), ed. anotada y adicionada por $V$. de la Fuente, Madrid, 1881. (José Gómez Centurión descubrió un ms. anterior, de $15^{87}$, de una breve relación biográfica de la Santa por el $P$. Ávila, base de la Vida de 1604 , y lo editó en el $B A H, 67,1915,592-600)$.-Vichnte de La FuenTF, introd. a los Escritos de Santa Teresa, BAAEE, t. 53 (1861), y en su ed. de las Obras, Madrid, 1881.-Migurl Mrr, Santa Teresa de Jesús. Su vida, su espiritu, sus fundaciones, Madrid, 1912; 2 ts.-P. Silverio dF Santa Trersa, Vida de Santa Teresa de Jesús, Burgos, 1937; 5 ts.-William Thomas Walsh, Saint Teresa of Avila: $A$ biography, Milwaukee, 1943. Hay traducción española por Mariano de Alarcón, Santa Teresa de Avila, Madrid, 1951; no la he visto; mis citas se refieren a la ed. inglesa.

10 P. Efren de LA MAdre De Dios, Tiempo y vida de Santa Teresa, en el t. 1 de las Obras completas de Santa Teresa (BAC), Madrid, 1951. (Véase lo que de esta biografía decimos en el Apéndice de la presente reseña).-P. Ferrlor. Hernández, Santa Teresa de Avila; estudio documentado sobre su nacimiento en la ciudad de Avila, pról. de Justo Pérez de Úrbel, Ávila, 1952. Lástima que este libro esté plagado de erratas, algunas de importancia, como "1505" por "1905" (p. 180), "1514" por "1914" (p. 181), "tomo LVX" por "LXV" (p. 181, n. 2), "Biblioteca motiva" por "mistica" (p. 182, n. s), etc.

$"$ Y según lo había evidenciado ya José Gómez Cfonturión, "La patria de Santa Teresa; duda resuelta con prueba documental", $B A H, 67$ (1915), 403-411 (no citado por Ferreol).

12 Véase también la reseña crítica (desfavorable) de J. M. Mohrdano, $R F E, 37$ (1953), 308-315, quien sigue a Ferreol.

${ }_{13}$ Melgar, p. 39o, sí había reparado en este nombre, pero, siguiendo su acostumbrada incredulidad, pregunta: "¿Quién puede ser Juan de Ahumada, al que llama [Alonso] hijo?", y da la siguiente respuesta, inesperada en un investigador serio: "Nadie; se trata indudablemente de una equivocación del traslado". Lea ahora el libro del P. Ferreol y se verá obligado a rectificar, como tuvo que hacerlo en otros tres casos análogos: el del bachiller Fernando de Santa Catalina, el del maestro Lorenzo Sánchez de Cepeda y el de Elvira de Cepeda (véase infra).-De hecho, el nombre de este hermano figura ya en el testamento de su padre, Alonso Sánchez de Cepeda (legalizado el 3 de diciembre de 1543), documento publicado por M. Serrano y Sanz, Apuntes para una biblioteca de escritoras españolas, t. 2, Madrid, 1905, pp. 490-492. 
Melgar, por Gómez Centurión y por José de Lamano y Beneite ${ }^{14}$. Por último, hemos contado, en especial para los parientes de Santa Teresa, con el libro de Pólit sobre la familia de la Santa en América ${ }^{15}$, original y extensa investigación con nuevos datos, rectificaciones a algunos biógrafos y correcciones a los Bolandistas ${ }^{16}$, y el artículo de Fernández de Bethencourt acerca de los parientes de la Santa en general ${ }^{17}$. Hemos prescindido, en cambio, del ensayo genealógico de los Cepeda por el Marqués de Ciadoncha, estudio un tanto confuso y en algunos casos erróneo, especialmente en las fechas ${ }^{18}$.

Con anterioridad se han trazado árboles genealógicos de Santa Teresa. Uno de ellos parece estar muy difundido por los conventos carmelitanos (Melgar, p. 377). Los Bolandistas hablan de un árbol genealógico del Marqués de Atalayuelas, por testimonio del carmelita fray Manuel de Santo Tomás (PóL.IT, p. 342). El P. Lorenzo de la Madre de Dios formó un árbol en 1618, a instancias del P. Gracián (Melgar, p. 105). Fray Antonio de la Madre de Dios compuso otro en Salamanca, en 1646 (Melgar, pp. 106 y 478). Uno moderno es obra de las carmelitas descalzas del primer monasterio de París ${ }^{19}$, incompleto, ya que no incluyen en él sino a cuatro tíos de la Santa, en vez de seis. Pólit insertó en su libro (p. 285) un árbol genealógico de la familia de Lorenzo de Cepeda en el Ecuador. En fin, Melgar publicó en 1915 (p. 104) un árbol que comprendía sólo trece nombres, aunque en otros trabajos (pp. 356-393) su genealogía es rica y detallada. El nuestro aumenta considerablemente el número de nombres.

"No se encontrará árbol más frondoso ni fructífero", escribe Fernández de Bethencourt (art. cit., p. 220). Se requeriría una lámina muy amplia para que abarcase todas las ramas. Por ello, lo exponemos en forma narrativa, la cual permite además anotaciones aclaratorias. No es fácil identificar el parentesco por medio de los apellidos, pues en aquel tiempo era potestativo escoger el apellido del padre, de la madre, del abuelo o de cualquier otro pariente. Recuérdese a Cervantes, quien tomó como segundo apellido el segundo de su padre, Saavedra (Frrz-

14 Véanse los tomos y páginas en los fndices de los ts. 1-115 del BAH (1877-1974), por V. Castañeda Alcover, Madrid, 1945 y 1947, Sección de autorcs, t. 2, pp. 65, 95 , 118 y 120, y Sección de nombres estudiados: "Teresa de Jesús", t. 2, p. 219.

${ }^{25}$ Manuel Ma Pólit, La familia de Santa Teresa en América, Estudio histórico, Friburgo de Brisgovia, 1905 .

10 P. Josef de Vandermoore, Acta Sanctae Teresiae a Jesu, Bruxelles, 1845.

17 Francisco Frernández de Bethencourt, "Los parientes de Santa Teresa", en sus Anales de la nobleza de España: Anuarios de 1882,1885 y 1886 , reprod. en su Libro para cuatro amigos, Madrid, 1909, y luego, revisado y ampliado, en el $B A H$, $5^{8}$ (1911), 216-223, y en sus Obras, Madrid, 1913, t. 1, pp. 51-59.

is Marqués de Ciadoncha, "Los Cepeda, linaje de Santa Teresa. Ensayo gencalógico", $B A H, 99$ (1931), 607-652. El autor entremezcla con vaguedad a los Cepeda de Ávila con los de Tordesillas; interrumpe la numerosa sucesión de la familia en Ávila $y$ se salta a Granada; no señala sus fuentes $y$, aunque hace constar que se basa en documentos y testimonios, nunca llega a indicarlos.-Véase además Francisco Llorente. y Poggi, Origen de los linajes de Avila desde su repoblación hasta el tiempo de Santa Teresa. Descripción de sus escudos, Ávila, 1915.

19 Oeuvres complètes de Sainte Thérèse de Jésus, trad. nouvelle, par les Carmélites du premier Monastère de Paris avec la collaboration de Manuel M. Pólit, t. 2, Paris, $19^{\circ} 7$, p. 400 (cf. FitA, $B A H, 65,19^{14}, 150$ ). 
maurice-Kelly, Hist. de la lit. esp., trad. de Bonilla, p. 291), en lugar del primero de su madre, Cortinas. Y Góngora eligió el sonoro apelativo materno en vez del Argote paterno, de terminación peyorativa.

He aquí, pues, nuestro cuadro genealógico:

Bisabuelos paternos: Alonso Sánchez y Teresa Sánchez, padres de Juan Sánchez de Toledo (judíos).-Hernando de Santa Catalina y Elvira Álvarez de Cepeda, padres de Inés de Cepeda (cristianos sin prueba en contrario).

Bisabuelos maternos: Juan Blásquez Dávila de Cordovilla, "gran caballero avilés". Se desconoce el nombre de la bisabuela materna.-Rodrigo de Oviedo y Maria de las Cuevas (cristianos viejos sin prueba en contrario).

Abuelos paternos: Juan Sánchez de Toledo, fallecido entre 1505 y 1508 (converso reconciliado) e Inés de Cepeda, muerta entre $15^{\circ} 4$ y 1507 (cristiana sin prueba en contrario). Juan tenía una hermana, madre de Enrique Hamusco, e Inés dos hermanos, Pedro y Antonio de Cepeda.

Abuelos maternos: Juan de Ahumada y Teresa de las Cuevas, casados en 1487, vecinos de Olmedo (Valladolid). Tuvieron seis hijos: Juan de Ahumada el mozo, Beatriz (madre de la Santa), Antonio y Sancho de Ahumada, María de las Cuevas y Juana de Ahumada (cristianos viejos sin prueba en contrario). Los cuatro últimos murieron jóvenes sin sucesión. Deudo de la madre debe ser un Pedro de las Cuevas, clérigo presbítero de Ávila.

Padres: Alonso Sánchez de Cepeda, nacido en Toledo en 1480 y muerto en Ávila el 24 de diciembre de $1543^{20}$, cristiano hijo de converso y de cristiana; casó en primeras nupcias, en $\mathbf{1 5 0 4}$, con doña Catalina del Peso y Henao, hija de don Pedro del Peso "ques un caballero desta dicha cibdad" (Alonso Contés, p. 95), y regidor perpetuo, y de Inés de Henao. Un descendiente de ésta, don Pedro de Henao, sería en 1642 regidor también de Ávila (Ferreol, p. 163). Don Pedro del Peso había contraído primeras nupcias con doña Francisca de Vera, de cuyo matrimonio nacieron Pedro del Peso el mozo y Juana de Vera. De su segundo, con Inés de Henao, tuvo tres hijas, la expresada Catalina, y María e Inés de Henao, ésta, segunda de su nombre, esposa que fue del alcalde de Villatoro, don Diego de la Nava (FErreol, pp. 15-16). En el tercer pleito (Alonso Contés, p. 108) actúa como testigo un Diego Gómez del Peso, clérigo, acaso emparentado con don Pedro. Testigos de la boda fueron el susodicho Pedro del Peso el mozo, medio hermano de la novia, y el bachiller Fernando de Santa Catalina, hermano del novio. Este primer casamiento de Alonso Sánchez dio el fruto de dos hijos, Juan y María. Doña Catalina murió el 8 de septiembre de 1507 , y a los dos años, a fines de 1509 , el viudo celebró segundas nupcias con una prima de la difunta, doña Beatriz Dávila y Ahumada, cristiana vieja. "La genealogía de los Ahumada abarca tres generaciones cuando menos de nobleza y sangre limpia, anteriores a Santa Teresa, según se desprende de documentos publicados, auténticos e indubitables" (Melgar, p. 371). Nació por los años de 1495 (Walsh, op. cit., p. 6), hija de Juan de Ahumada y Teresa de las Cuevas. Fecunda fue esta unión que produjo diez vástagos, el tercero la Santa. Vio la luz ésta el 28 de marzo de 1515 y fue bautizada el 4 de abril, siendo sus padrinos don Francisco de Vela Núñez ${ }^{21}$, hermano de don Blasco, primer virrey del Perú, pariente, al parecer, de la madre, y doña María del Águila, hija de don Francisco González Paja-

20 De una declaración del segundo pleito deduce Alonso Cortés (p. 10g) que el padre de la Santa nació en 1480. Los biógrafos daban los años de $1474,147^{6}$ o 1485. Pólir (p. 51) dice erróneamente que murió el $1^{\circ}$ de febrero de 1544 .

21 Descendientes de Vela Núnez fueron los condes de Guevara y de Oñate y los marqueses de Tabladillo, hoy duques de la Roca. Doña María del Águila pertenecía a la familia de los marqueses de Villaviciosa, las Navas y Villafranca (Pólir, p. 332). 
res, regidor de Ávila, emparentado por afinidad con el padre. Le impusieron el nombre de Teresa, en recuerdo quizá de su bisabuela paterna y de su abuela materna. El nombre completo que correspondía a la Santa era, pues, Teresa Sánchez y Dávila, con los primeros apellidos de su padre y madre; pero ella los desechó (el de Sánchez tal vez por muy común) y prefirió los segundos respectivamente de Cepeda y Ahumada. Su madre, doña Beatriz, por el apellido Dávila, estaba vinculada a don Francisco Dávila, de la encumbrada casa de Villatoro, señor de Salobralejo, cuya renta anual ascendía a un millón de maravedís, marido de doña Guiomar de Ulloa (n. 1527), hija de don Pedro de Ulloa, regidor de Toro, y de doña Aldonza de Guzmán, avilesa. Doña Guiomar dio vida a don Luis Dávila y a doña Antonia de Guzmán, y enviudó en 1552. Viuda ya, llegó a ser amiga entrañable de Teresa, a quien auxilió muy eficazmente en sus fundaciones. Doña Beatriz testó el 24 de noviembre de $15_{28}^{28}$, y se supone que falleció antes de terminar el año, pero no se sabe de cierto $^{22}$. Teresa cumplía los trece años. El viudo, que vivió quince años más, no se volvió a casar y llevó una vida retirada y religiosa ${ }^{23}$. La Santa sobrevivió a su padre treinta y nueve años; murió el 4 de octubre de $\mathbf{1 5 8 2}$.

Tíos paternos, seis: Pedro Sánchez de Cepeda, que casó (en 1508?) con doña Catalina del Águila, hija de Álvaró del Águila y de Isabel Álvarez de Herrera, y hermana de Ana, mujer de don Francisco González Pajares. Tuvo un hijo y una hija. Era viudo ya en 1522 , y se hizo fraile.-Ruy (o Rodrigo) Sánchez de Cepeda, que contrajo matrimonio (en 1514?) con doña Isabel del Águila, hija de don Fernando Álvarez del Águila "ques caballero principal" (Alonso Cortés, p. 95), y tuvo por hijas a doña Mencía del Águila (ibid., p. 101), y a doña Elvira de Cepeda, segunda de este nombre (véase infra, Primos). Don Fernando falleció el 28 de julio de 1522 , y doña Isabel antes de 1525.-Francisco Álvarez de Cepeda, nacido hacia 1495 (no 1595, como se lee por errata en Alonso Contés, p. 103), de quien no nos dice el testigo sino que "se casó, agora de un mes acá", en 1520 (ibid., p. 98). Su esposa era doña María de Ahumada, hija de Juan Álvarez Cimbrón y Catalina de Tapia y nieta de Toribio Cimbrón (Melgar, p. 478), la cual doña María otorgó tes-

"2 E1 P. Fita, por la declaración de un testigo, calcula que dona Beatriz falleció en $153^{\circ}$ o 1531 (BAH, 65,1914 , p. ${ }_{155}$, n. 5 , y p. 365$)$, y el P. Silverio (op. cit., t. 1 , p. 94, n. 2) cree que la muerte sobrevino en 1529 o a principios de 1530 . La Santa dice, sin duda por equivocación, que tenia doce años, o algo menos, cuando perdió a su madre. Esto sería en 1527 . De creer a Teresa, doña Beatriz habría firmado su testamento un año después de muerta. Deben tenerse presentes las tablas cronológicas de Santa Teresa por V. DE LA Funnte ( $B A A E E$, t. 53, pp. 11-15, y en su ed. de las Obras, Madrid, 1881 , t. 1, p. ii), que fue el primero en formarlas; le siguió el P. Mir (Espiritu de Santa Teresa, Madrid, 1898, p. xxviii, y Santa Teresa de Jesús, su vida, etc., Madrid, 1912, t. 1, p. 32), rectificadas por Melgar (BAH, 69, 1916, 320). Otra tabla cronológica publicó E. Allrson PEFrs (The complete works of Saint $T_{e}$ resa of Jesus, New York, 1946, t. 1, p. xxii). Véase además Enriqur Jorge Pardo, "Rectificaciones necesarias en la cronología teresiana", Manresa (Bilbao), 22 (1950).

${ }^{23}$ Dos inventarios publicados por Serrano y SANz, Apuntes, t. 2, pp. 482 y 492 , nos revelan algunas de las lecturas de Alonso: El Retablo de la vida de Christo, por Juan de Padilla, el Cartuxano (en una ed. anterior a 1507, fecha del primer inventario); un Tratado de la missa; Los siete pecados (antes de 1507), acaso de Francisco de Guzmán, autor de los Triumphos morales (1557); el De consolación de Boecio, en la trad. de Antonio de Ginebreda (Sevilla, 1511; ej. en la H. S. A.); los Evangelios $y$ epistolas de fray Ambrosio Montesino (Amberes, ${ }_{1543}$; H. S. A.), y unos Sermones. Es probable que le perteneciera también un ejemplar del Espejo de conciencia, incautado por el alguacil en casa de su hermano Pedro (Alonso ConTés, p. 86); en la H. S. A. hay un ejemplar del Espejo de la consciencia... por un fraile menor [fray Juan Bautista de 'Viñones], Logroño, $15^{\circ} 7$ ( $1^{a}$ ed., rarísima; ejemplar distinto del que describen Gallardo, Ensayo, t. 1, núm. 618, y MéndeZ, p. 399). 
tamento el 9 de junio de 1569 . De este matrimonio nacieron, por lo menos, siete hijos (véase infra, Primos).-El bachiller Fernando de Santa Catalina (que tomó el nombre de su abuelo), ausente de todas las genealogías, hasta que topó con él Serrano y Sanz (Apuntes, t. 2, p. 479), como testigo en la escritura de dote otorgada en 14 de noviembre de $15^{\circ} 4$, donde se expresa su nombre y parentesco: "hijo de Juan Sánchez de Toledo y hermano del novio" (Alonso) en los esponsales de éste con Catalina del Peso ${ }^{24}$.-El Maestro Lorenzo Sánchez de Cepeda o Maestro Cepeda, sacerdote, en quien no se ha parado mientes hasta hace poco, pues la Santa, al parecer, nunca lo nombra. Sin embargo, Alonso, en su testamento, otorgado antes del 3 de diciembre de 1543 , lo designa como uno de sus testamentarios, haciendo constar que es su "hermano" ${ }^{25}$.-Elvira de Cepeda, primera de este nombre, tía de la Santa, la única hembra entre estos cinco varones, unida en matrimonio con Hernando Mejia, de quien ya había enviudado en 20 de febrero de $1525^{.26}$. Los cinco tíos y la tía: hijos de converso. Las mujeres desposadas en Ávila: cristianas viejas, pertenecientes a las familias de los regidores, caballeros hidalgos de la ciudad, de "limpia sangre", según deducimos de la prueba testifical del pleito. Respecto a la casada en Salamanca, sólo sabemos que usaba el "doña".

Hermanos, doce: dos del primer matrimonio, Juan ( 1505 ?) y María ( 1507 ?), y diez del segundo, contando a Teresa, en el siguiente orden cronológico: Rodrigo (1511) ${ }^{27}$, Hernando (1512?), Teresa (1515), Lorenzo (1519), Antonio (1520), Pedro (1521), Jerónimo (1522), Agustin (1527), Juana (1528) y Juan (1529?). Si esta última fecha es exacta, como da a entender el P. Ferreol, ya que la madre no lo menciona en su testamento de 24 de noviembre de $15^{28}$, se robustece la creencia del $P$. Silverio de que doña Beatriz falleció en 15290 1530.-El primogénito Juan, el del primer matrimonio, usó los apellidos Cepeda o Vázquez, más éste que aquél, o ambos, Vázquez de Cepeda, y murió, capitán de infantería, en la guerra de Italia, en 1525 , de un arcabuzazo. Muerto él, bautizaron al recién nacido en 1529 (?) con el mismo nombre, quizá en memoria suya.-María, Rodrigo, Lorenzo y Jerónimo optaron por el segundo apellido del padre, Cepeda, y Hernando, Teresa, Antonio, Pedro, Agustín, Juana y el segundo Juan llevaron el segundo de la madre, Ahumada. Hernando a veces fluctuaba entre ambos.-Maria de Cepeda casó en 1531 con don Martín de Guzmán Barrientos (muerto en 1561 o antes), hijo de Francisco de Guzmán y de Isabel de Barrientos. De María y Martín nació Diego de Guzmán Barrientos, que casó en 1561 con doña Jerónima de Tapia (véase infra, Primos). Hija de éstos fue Catalina de Guzmán, que casó a su vez con

24 Este documento fue reproducido por el P. FrTa $\left(B A H, 5^{8}, 19^{11}, 3\right.$ ss.) y por MELGAR (p. 368). Los documentos descubiertos por Alonso CorTf́s confirman (pp. 88.89) la noticia de Serrano y Sanz, con el testimonio de dos testigos que conocieron personalmente al bachiller Fernando de Santa Catalina.

${ }^{25}$ Serrano y Sanz, Apuntes, t. 2, p. 490; Fita, BAH, 65 (1914), 155, nota. El incrédulo Melgar, pp. 390-391, pensó que se trataba de un error de copia, en vez de "hijo", pues lo confundía con el hijo Lorenzo de Cepeda; pero luego rectificó.

${ }_{26}$ Publicó esta noticia por primera vez el P. FITA, $B A H, 65$ (1914), 146-150 y 350-352. También se equivocó Melgar, p. 110, al afirmar que era sobrina y no tía; pero tuvo que desdecirse (pp. 348-356) ante la prueba de una carta autógrafa de la propia Santa, del año $154^{1}$, que se conserva actualmente en el valioso archivo teresiano del mismo Melgar, en Ávila, donde posee además una rica biblioteca abierta a los investigadores.

${ }^{27}$ El P. Ferreol (pp. 12-14), basándose en el Libro de recreaciones de María de San José (Salazar), escrito a fines del siglo xvr e impreso por el P. Silverio (Burgos, 1913), p. 66, sostiene que no precede en nacimiento Hernando a Rodrigo, como se creía, sino Rodrigo a Hernando, pues Rodrigo nació exactamente cuatro años antes que Teresa, es decir el 28 de marzo de $15^{11 .}$ 
don Juan del Águila, hijo de Gil González del Águila y doña Constanza Manuel.Rodrigo de Cepeda, el compañero de Teresa durante su infancia, nació el 28 de marzo de 1511, se trasladó a Indias y combatió en la batalla de Añaquito o Iñiquito en el Perú (18 de enero de ${ }^{1546}$ ), militando junto al virrey don Blasco Núñez Vela, hermano del padrino de Teresa. Tuvo una carrera distinguida en Chile y fue muerto en $155^{6}$, de capitán, en la conquista del Río de la Plata (Ribera; Pólit, p. 53), o en ${ }_{1557}$, luchando en Chile contra los araucanos (P. Silvlerio, t. 1, p. 137; Alonso Cortés, p. 103)--Hernando de Ahumada nació en 1512 , se trasladó también a Indias y fue herido en el Perú en la batalla de Añaquito. Parece que regresó a España y contrajo matrimonio con doña Leonor Pćrez, noble señora avilesa, en la que tuvo una hija, doña Leonor de Ahumada, que casó con don Luis de Soria, de quienes descendieron familias de la aristocracia, entre ellas la de los marqueses de Atalayuelas (Melgar, p. 377, n. 3). Luego volvió a las Indias y murió en Pasto en ${ }_{1574^{28}}$.-Lorenzo de Cepeda (1519-1580), el preferido de Teresa durante su edad adulta, se halló igualmente en la batalla de Añaquito. Casó en Trujillo, en $155^{6}$, con doña Juana de Fuentes $\left(1539^{-1} 5^{67}\right)$, hija de don Francisco Fuentes, uno de los primeros conquistadores, y de doña Bárbara de Espinosa, hija del licenciado don Gaspar Espinosa, oidor de la Audiencia de Santo Domingo y primer gobernador de Panamá y reino de Tierra Firme (Pólit, p. 78). Se domicilió en Quito, perteneciente entonces al virreinato del Perú, y allí obtuvo un rico repartimiento de indios, y desempeñó sucesivamente los cargos de regidor del cabildo, tesorero de las cajas reales, alcalde, teniente gobernador y capitán general ${ }^{29}$. Enviudó en ${ }_{1567}$ y volvió a España en ${ }_{1575}$, después de más de treinta y cuatro años de ausencia, con tres de sus hijos, niños de corta edad, llamados Francisco, Lorenzo y Teresita. Otro hijo, de nombre Esteban, nacido en ${ }_{15} 6_{3}$, falleció en Quito el mismo año del regreso (Pólit, pp. 285 y 334). El padre, que se había enriquecido con sus encomiendas de indios, había auxiliado económicamente desde América a Teresa en sus fundaciones y continuó haciéndolo en España, hasta su muerte, acaecida en 26 de junio de ${ }_{15}^{80}$. Habia otorgado testamento el 12 de abril de 1578 , y codicilo con un memorial el 28 de julio del mismo año (Pólrt, pp. 353-368, publica íntegros estos documentos, tomando parte de Serrano y SANz, Apuntes, t. 2, pp. 500-5o6).-Antonio de Ahumada sintió la vocación religiosa y quiso meterse fraile, pero no lo logró por falta de salud y marchó a Indias, donde murió a poco. Esto se lee en Pólit (p. 58); pero el P. Silverio (t. 1, p. 149) manifiesta que pereció en la batalla de Añaquito, en 1546. - Pedro de Ahumada no tuvo suerte en América; regresó a Ávila pobre y enfermo por los años de 1576 . Rasgos interesantes de su carácter y de su vida asoman en las fojas del tercer pleito descubierto por Alonso Cortés (pp. 104-109), entablado por aquél contra su sobrino Francisco de Cepeda Ahumada, el hijo mayor de Lorenzo, por cuestión de dineros. Pedro ganó el pleito. En otro pleito muy distinto, el promovido sobre el lugar del enterramiento de Santa Teresa, declaró "que es lego hijodalgo, buen cristiano, temeroso de Dios, y se confesó y comulgó no ha muchos días" $(B A H, 68$, 1916, 111). Murió el 19 de febrero de ${ }_{15}^{89}$.-Jerónimo de Cepeda, compañero dc Lorenzo en el viaje que los condujo a Indias en noviembre de 1540 , le sucedió en la Tesorería de Quito en 1567 , y cuando se restituía a su patria en abril

${ }^{28}$ Datos de la documentación del Real Patronato de Indias, en la ciudad de Ávila y villa de Alba de Tormes, recogidos por J. Gómez Centurión, "Relaciones biográficas de Santa Teresa hechas en 1587 ", $B A H, 68$ (1916), 102 y n. 3.

${ }^{29}$ Carta de Teresa a su hermana Juana (19 de octubre de 1569 ), publicada en su Epistolario por el P. Silverio, Bibl. Mistica Carmelitana, t. 1, p. 47. Más detalles se encontrarán en Póltr, pp. 77, 123-163 y 336-373, quien se sirvió de los documentos del Archivo de la Tesoreria de Quito y del Archivo de Indias. 
o mayo de 1575 , cayó enfermo y falleció, de paso por Panamá, en el puerto de Nombre de Dios (carta citada de Teresa a Juana, y Pólit, pp. 342-345). -Agustin de Aliumada, el menor de los hermanos, combatió en Añaquito, pasó a Chile, "se halló en diez y siete batallas" (Melgar, p. 378 ), volvió de capitán al Perú, fue alcalde de Cañete y gobernador de Quijos, y murió en Lima en 1591. - La hermana Juana de Ahumada casó con Juan de Ovalle, propietario y regidor de Alba de Tormes, y tuvieron por sus hijos a Gonzalo y José de Ovalle y a Beatriz de Ovalle y Ahumada (Ribera, lib. III, cap. 15, p. 1o8; véase infra, Sobrinos). Juana expiró en 1589. -Del último hermano, Juan de Ahumada, no se tienen más noticias que las suministradas por el $\mathrm{P}$. Ferreol, a que hemos hecho referencia. Nacido acaso en 1529 , moriría adolescente, entre 1543 , fecha del testamento de su padre, en el que lo incluye entre sus hijos, y 1544 , fecha del pleito de la testamentaría, en el que ya no se le enumera. Dejaría de existir, pues, a los quince años de edad.

Primos: En una familia tan numerosa se multiplicaba la prole. Teresa contaba con un enjambre de primos. He aquí unos cuantos que ocupan un lugar en la vida de la Santa. Jerónima de Tapia, hija de Francisco Álvarez de Cepeda, a pesar del apellido, y los otros hijos de éste, Pedro Álvarez o Perálvarez Cimbrón y Vicente de Ahumada, sacerdote (FERREOL, p. 118), cura párroco de la aldea de Villanueva del Aceral, quien otorgó testamento el 9 de diciembre de $157^{\circ}$ (Melgar, BAH, 68, 1916, 255). -Primas asimismo doña Inés y doña Ana de Tapia, monjas carmelitas con los nombres de Inés de Jesús (15531634) y Ana de la Encarnación, según nota del P. Gracián (Mir, t. 1, p. 22). - María Dávila (1541-1602), en el claustro Maria de San Jerónimo, priora, hija del acaudalado Alonso Álvarez Dávila (WALsh, pp. 245-246) y de doña Mencía de Salazar (Carmelitas de París, op. cit., t. 3, 1909, p. 326). -Doña Elvira de Ciepeda, segunda de este nombre, que contrajo nupcias con Pedro Mexía y procreó a tres hijos, Diego, Mencía e Isabel Mexía. Diego casó con Ana de Vergara, cuyo hijo don Diego Mexía de Cepeda $\left(\dagger{ }_{1627}\right)$ fue caballero de Santiago y tuvo por mujer a doña María Dovalle y Valdivieso ( $\dagger_{1650}$ ). Este caballero de Santiago era, pues, sobrino en tercer grado de Santa Teresa. -Diego de Cepeda Álvarez, hijo de Francisco Álvarez de Cepeda, casó con Beatriz de la Cruz y Ocampo, de quien tuvo a María de Ocampo (véase infra, Sobrinos). -Prima segunda, doña María de Ahumada, esposa del dicho Francisco Álvarez de Cepeda y sobrina de doña Beatriz, madre de Teresa.

Sobrinos: Más numerosos aún que los primos son los hijos de los hermanos de la Santa. He aquí los más relacionados con la tía: Teresita de Ahumada, no de Cepeda, hija de Lorenzo, nacida en Quito en ${ }_{1566}$, no en ${ }^{1} 5^{6} 7$ ni en 1568, como han dicho los biógrafos (PólrT, pp. 98 y 346), que tomó el nombre de Teresa de Jesús, al igual de su tía, cuando entró monja. Murió en 1610. - Maria de Ocampo (Maria Bautisia en religión), priora, aficionada, como lo fue su tía, a la lectura de los libros de caballerías (P. Silverio, t. 2, Pp. 13-14; WALSH, p. 174). -Beatriz de Ovalle y Ahumada (Beatriz de Jesús en el claustro) (1560-1639), priora, y su hermano Gonzalo de Ovalle (1557$\left.{ }_{15} 5_{5}\right)$. Su otro hermano, José, murió el mismo año que nació: 1561 . -Y los hermanos Francisco (1560-1617) y Lorenzo (1562-1627) de Cepeda Ahumada [y Fuentes], nacidos en Quito. Francisco heredó la fortuna del padre; vivía en Madrid y alli emparentó con la nobleza por su matrimonio en $15^{80}$ con doña Orofrisia de Mendoza y Castilla, hija de don Francisco de Mendoza y de doña Beatriz de Castilla y Mendoza, prima hermana del Duque de Alburquerque y sobrina del Duque del Infantado, parienta de los marqueses de las Navas y de Velada (carta de Teresa, 27 de diciembre de 1580; Gómez Centurión, $B A H$, 68, 1916, 214, n. 1). Lorenzo habia marchado al Perú con el fin de administrar la encomienda que allí poseía su padre, renunciando antes de salir de 
Ávila a la herencia de éste en favor del mayorazgo Francisco. Mas éste derrochó su hacienda a tal extremo, que se vio compelido a emigrar a Indias (ca. 1591), con objeto de rehacer su caudal. No lo logró sin embargo, y allá murió en la miseria en 1627 . En cambio, su hermano Lorenzo prosperó, casó en Quito, en 1581, con doña María de Hinojosa, natural de Santo Domingo, hija del oidor y fiscal don Pedro de Hinojosa $(\dagger 1581)$ y de doña Ana de Estebes y Santisteban, y fundó una numerosa familia (tuvo seis hijos), originaria de la rama de los Cepeda, que aún dura en el Ecuador y el Perú (Pól.tT, pp. 266, 340). Francisco no dejó sucesión.

Hemos llegado a la quinta generación, con la cual damos remate al cuadro genealógico de la Santa. Las cinco generaciones que hemos abarcado son, pues: 1 ) la de los bisabuelos de Santa Teresa, 2) la de los abuelos, 3) la de los padres y tíos, 4) la de los hermanos y primos, y 5) la de los sobrinos. Un número no corto de parientes directos de la Santa, de origen judaico, fueron religiosos: siete monjas, un religioso y tres clérigos. Además, otros parientes lejanos o por afinidad abrazaron la vida conventual y sacerdotal, como doña Quiteria Dávila, monja, prima de la Marquesa de Velada (Walsh, p. 407), el suegro de Ruy Sánchez de Cepeda, don Fernando Álvarez del Águila, jesuíta (P. Pons, ed. de la Vida por Ribera, p. 122, n. 1), Diego Gómez del Peso, clérigo, Pedro de las Cuevas, clérigo, y don Francisco de Salcedo $(\dagger 1580$ ), pariente político por su casamiento con doña Mencía del Águila, que vistió la sotana de sacerdote al enviudar (P. Silverio, t. 1, pp. 367-371). Otro deudo lejano, Rafael Mexía, aunque no eligió la vida religiosa, hizo donación a Teresa de una casa en Duruelo para establecer en ella el primer monasterio de frailes descalzos (WALSH, p. 337).

Sostenía la Santa trato con judíos conversos, con algunas de cuyas familias guardaba estrecha amistad, en especial con los Bracamontes. Don Diego de Bracamonte era antiguo amigo de Teresa; él compró la casa donde nació la Santa ${ }^{30}$, después de la muerte de ésta (P. SilveRio, t. 1, p. 65). Igualmente don Francisco Barros de Bracamonte y su viuda doña Ana de Jimena, cuya hermana era monja. Otra monja, doña Francisca, llevaba el apellido Bracamonte y era hermana de don Jerónimo de Guzmán, rico y noble descendiente de los Bracamontes. Y otro Guzmán, don Francisco († 1573), canónigo de la catedral de Ávila, era hijo de Mosén Rubí de Bracamonte. De todos ellos solicitaba fondos Santa Teresa para sus fundaciones (WALsh, p. 392). William Thomas Walsh, católico norteamericano, hace notar que, por una de las ironías de la historia de España, en la época en que la Inquisición perseguía a los nuevos cristianos de dudosa ortodoxia, se construyó con dinero judío la iglesia de Nuestra Señora de la Asunción de Ávila, tan relacionada con la vida de Santa Teresa. Mosén Rubí de Bracamonte había cumplido la última voluntad de doña María de Herrera, católica de-

${ }^{30}$ La casa estaba situada cerca de la morería de Ávila (Warsh, p. 3), "a la linde del barrio judio" (P. Efrén, p. 178). Cf. Marqú́s de Foronds, "La casa de la Santa", en su folleto La Santa de Ayila, datos históricos, Madrid, 1907 (véase BAH, 100 , 1932, 134 y n. 1); ID., "La alcoba natalicia de Santa Teresa", $B A H, 57$ (1910), 425428, y P. FrrReol, "El pleito sobre la casa de la Santa", en su op. cit., p. $115^{-13^{8}}$, con un plano. 
vota, que dejó un legado para la construcción de una iglesia ${ }^{31}$. Los Bracamontes constituían una prolífica y distinguida familia de origen judio emparentada con varias de las familias nobles de España: los Cerda y Carvajal, Téllez de Girón, Fernández de Velasco, los Condes de Contamina y de Peñaranda de Bracamonte y los Duques de Medina de Rioseco ${ }^{32}$. Descendientes asimismo de Mosén Rubí fueron don Alvaro Bracamonte y su mujer doña Isabel Dávila y los Condes de Parcent ${ }^{33}$. Otro amigo de raza hebrea, que auxilió a Santa Teresa en los preparativos de la fundación del convento de Palencia, fue el canónigo Francisco Reinoso, sobrino de don Jerónimo Reinoso, obispo de Córdoba, que gozaba de la amistad del papa Pío V (WALsh, pp. 562-563).

Preguntada cierta vez Teresa por el $P$. Jerónimo Gracián acerca de sus antepasados, contestó ella: "Me basta ser una hija de la Iglesia católica, y más me turbaría haber cometido un pecado venial, que descender de los más bajos y viles hombres de la tierra" (WALSH, p. 5). Esta respuesta, y más aún su opinión acerca del uso del don, da base para sospechar que Teresa conocía el verdadero linaje de sus ascendientes. Consignan sus biógrafos que la Santa despreciaba especialmente todo orgullo de familia o de raza (Walsh, p. 47). Cuando regresó a Ávila, procedente del Perú, su hermano Lorenzo con sus tres hijos usaron el don, lo que levantó una protesta entre la población abulense, pues se pretendia que Lorenzo y su familia carecían de tal derecho ${ }^{34}$. Enterada Teresa,

31 Véase M. DE Foronda, "Mosén Rubín, su capilla en Avila y su escritura de fundación”, $B A H, 63$ (1913), 332-350.

32 Walsh, p. 160, quien da como referencias la Historia de Avila por Juan Martín Carramolino, Madrid, $1872-1873$, t. 3, pp. 114 y 238 ss., y la Enciclopedia de Espasa, t. 33, p. 741. Nosotros hemos cncontrado tambićn datos en Fernández DE Bethencourt, $B A H, 5^{8}$ (1911), 221.

33 "Muchas ilustres familias se habian mezclado durante la Edad Media con gente de raza judía, a causa de su rango, su fortuna y la frecuente belleza de sus mujeres" (CASTRo, España en su historia, p. 538). Se ve que continuaba la unión al alborear la Edad Moderna. "Una larga reseña de nombres ilustres emparentados con quienes habían sido judios, sin excluir a personas de sangre real", se encuentra en el libro de Frrmín Caballero, Conquenses ilustres: Doctor Montalvo, pp. 243 ss., cit. por Castro (p. 539), quien añade: "En otros dos bien conocidos textos del siglo xvi se mencionan las familias con antecedentes judaicos. Uno es el Libro verde de Aragón (publicado en la Rev. de España, $188_{5}, \mathrm{CV}, \mathrm{CVI}$ ) y el otro El Tizón de la nobleza de España, del cardenal Francisco Mendoza y Bobadilla, arzobispo de Burgos, en donde demuestra que no sólo sus parientes, los Condes de Chinchón (acusados de poco limpia sangre), tenían antepasados hebreos, sino casi toda la aristocracia de aquella ćpoca" (pp. 539-540).-En vista de la rarcza de las ediciones del Tizón de la nobleza, remite Castro al resumen de la Enciclopedia de Espasa, artículo "Nobleza". Véase también R. Foulcié-Delbosc, RHi, 7 (1900), 246-247, y 8 (1901), 510-512; M. Hlirrero García, "La nobleza", RFE, 14 (1927), 41, y H. Serts en el Homencije a Huntington (Wellesley, 1952), p. $55^{6}$.

34 "Que ningún judio se llame en nombre don por escripto nin por palabra", ley de las Partidas, VII, 24,8 , cit. por Castro, p. 531. En el domicilio de Francisco Alvarez de Cepeda, tío de la Santa, se halló un ejemplar de las Partidas (Alonso Cortŕs, p. 86), y otro ejemplar figura en un inventario del padre de la Santa (véase nuestra nota 23). Según recuerda KAYserLing (The Jewish Encyclopedia, t. 11, 496b), a instancias de San Vicente Ferrer, y redactada por el obispo Pablo de Santa María, converso él misno, se promulgó en encro de 1412 una pragmática, en nombre del rey-niño don Juan II, en una de cuyas cláusulas se ordenaba que los judios no usaran el título de don. 
que se hallaba en Sevilla, escribió el 29 de ábril de 1576 una carta a su sobrina, la monja María Bautista (publ. en su Epistolario, Bibl. Mística Carmelitana, t. 1, pp. 229-23o), en la que mostraba sus dudas respecto a la posesión por su familia de dicho derecho. Decía, en resumen: Todos los que tienen vasallos en las Indias usan allí el don; pero cuando mi hermano y sus hijos regresaron, pedí al padre que no permitiera a sus vástagos hacerlo aqui, y le di razones; ahora en Ávila no se habla de otra cosa, lo cual es vergonzoso. "Y cierto, a mí me dan en los ojos, por lo que a ellos toca"; pero por lo que me toca a mí nada importa, pues esto es poco comparado con otras cosas que de mí dicen. "Yo lo tornaré a decir a su padre. Harto me mortifica cada vez que se lo oigo". Desde luego, en sus conventos prohibió el uso del doña.

Ya hemos visto que la cuestión de la raza no era obstáculo para pertenecer al clero regular o secular. Veamos otros casos de importancia. Entre los nueve compañeros de San Ignacio de Loyola que en 1534 pronunciaron sus votos en la capilla de Montmartre, y luego, en $153^{8}$, marcharon a Roma con el fin de fundar la Compañía de Jesús, había uno descendiente de judíos (WALsh, p. 120). San Ignacio no abrigaba prejuicio alguno a este respecto ${ }^{35}$. El jesuíta Juan Alonso de Polanco, su secretario, el único que le acompañó en la hora de la muerte, era de origen judío (WALsh, p. 181), y su buen amigo el P. Laínez, que le sucedió como general de la Orden, provenía de una familia de conversos ${ }^{36}$. Se dijo que el P. Nicolás de Bobadilla era hijo de un tornadizo y que "por sus pies fue a la pila" (bautismal) (Epistolae mixtae, Monum. Hist. S. I., t. 2, p. 656). Ingresaron también en la orden algunos discípulos del maestro Juan de Ávila que descendían de familias israelitas, y el mismo apóstol de Andalucía, tan adicto a los jesuítas, era converso (Cereceda, op. cit., t. 1, p. 22). Hubo, en cambio, en la Compañía unos cuantos "malcontentos", la mayor parte de raza judía, que fueron expulsados (Astráin, op. cit., t. 3, pp. 55 ss.). Desde entonces sólo se admitía a los nuevos cristianos cuyo catolicismo fuera plenamente probado (Walsh, p. 182). Aun hoy, los candidatos de ascendencia judaica pueden ingresar en la Orden, si cumplen con aquellos requisitos y obtienen una dispensa del Papa (WALSH, p. 181, n. 12). Los frailes jerónimos admitieron al principio en su orden a judíos bautizados ${ }^{37}$. "La Orden dominicana contó en su seno ilustres conversos" "38. Y no olvidemos los casos de Pablo de Santa María, obispo de Burgos; sus hijos

${ }_{35}$ Véase M. Batalllon, "Les commencements de la Compagnie de Jésus en Espagne", $A C F, 46$ (1946), 164-168, y CASTRO, p. 616, nota.

${ }_{30}$ Véase Antonro Astríin, S. J., Historia de la Compañia de Jesús en la Asistencia de España, 2a ed., Madrid, 1912-25, t. 1, pp. 73-74, y Frliciano Cereceda, S. J., Diego Lainez en la Europa religiosa de su tiempo, Madrid, 1945, t. 1, pp. 18-22. Astráin se refiere a los moros y judíos "que a fines del siglo $\mathrm{xv}$ vivian en tanto número mezclados con la población católica" (t. 1, p. lxxxvii). En cuanto a la tolerancia, Mr. Walsh, ferviente católico, pero nacido en un pais tolerante, en el que existe libertad de cultos, escribe: "Laínez mostró de modo ejemplar las más nobles cualidades del que fue el pueblo elegido, que dio al mundo una Madre y un Redentor" (pp. 181-182).

${ }_{37}$ A. Castro, Aspectos del vivir hispánico, Santiago de Chile, 1949, pp. 105 y 111 (véase el cap. "Conversos y jerónimos", pp. 90-114). Castro se documenta en la Historia de la Orden de San Jerónimo, del P. Singüenza.

$3 s$ Eugenio Asensio, "El erasmismo y las corrientes espirituales afines. Conversos, franciscanos, italianizantes", $R F E, 36$ (1952), p. 68. 
(tenidos antes de su conversión), Alonso de Cartagena ${ }^{39}$, sucesor del padre en aquel obispado, y Gonzalo de Santa María, obispo de Astorga, Plasencia y Sigüenza; el obispo de Coria; fray Pablo de La Caballería, obispo de Malta; fray Alonso de Espina, fray Alonso de Oropesa, fray Diego de Valencia y Jerónimo de Santa Fe; el cardenal Juan de Torquemada y su sobrino Tomás de Torquemada ${ }^{40}$, primer inquisidor general ${ }^{* 1}$; el arzobispo Hernando de Talavera (BATAILlon, Erasmo, t. 1, p. 69, n. 24): Melchor Cano, "de sangre mezclada" (Asensio, p. 69); fray Francisco de Vitoria y fray Alonso de Cabrera, dominicos; Francisco Suárez y Francisco Sánchez, jesuítas, y Luis de León, agustino.

Entre los profanos recordemos a los escritores Pedro Alfonso, Sem Tob de Carrión, Álvar García de Santa María, hermano de Pablo, Juan Poeta de Valladolid, Pedro Ferrús, Antón de Montoro, Diego de Valera, Hernando del Pulgar, Alfonso de la Torre, Juan de Mena, Ro. drigo Cota, Fernando de Rojas, Alfonso de Zamora, León Hebreo, Juan Luis Vives, Andrés Laguna, Juan de Lucena, Jorge de Montemayor, Mateo Alemán, Antonio Enríquez Gómez y otros ${ }^{42}$.

No nos debe sorprender a los españoles, hijos de los iberos, de los vascos, de los celtas, de los romanos y de los godos, el crecido número de literatos y religiosos descendientes de hebreos, pues éstos trajeron al inmigrar, desde la más remota antigüedad, una de las características de su raza, la de cultivar la poesía y la teología a la par que la filoso.

29 Véase Fr. Luciano Sfrrano, Los conversos don Pablo de Santa Maria y don Alfonso de Cartagena, Madrid, 1942.

40 Según Hernando del Pulgar, su coetáneo (CASTro, España en su hist., pp. 546, 557 y 558 ). El apellido Torquemada pertenecía a varias familias de ascendencia judaica. Fi padre de la amante que tuvo Colón en Córdoba, Beatriz Enríquez, se llamaba Pedro de Torquemada, era judío de origen y "primo lejano del inquisidor general" (Josí de r. TORRE y Del CrRro, Beatriz Enriquez de Harana y Cristóbal Colón. Estudio y documentos, Madrid, 1933).

41 Lo que no significa que el espíritu judaico influyera en la Inquisición; la persecución terrorífica de este y otros conversos distinguidos contra los miembros de su propia raza, podría explicarse piadosamente con la frase muy española de ser "más papista que el Papa".

${ }^{42}$ Véase José Amador de los Ríos, Estudios históricos, politicos y literarios sobre los judios de España (1848), ed. de Buenos Aires, 1942, pp. 282-315, 317-434 y 489500; A. Castro, España en su hist., pp. 475 n., 479, 539, 540, 553-557, 559, 569-578, $580,5^{81}, 586,629$ y $682-685$ (Vives); su artículo de $H, 35$ (1952), 161-172; Aspectos del vivir hispanico, pp. 140-142 (Laguna), 142-149 (Montemayor), 88 y 107-108 (Lucena); La realidad histórica de España, p. 659 (Vitoria); M. Batalllon, Erasmo, t. 2, pp. 279-304 (Laguna), 208-209 (Montemayor), $217^{-221}$ y 237-24o (Vives); M. J. BENARDETE, Hispanic culture and character of the Sephardic Jews, New York, 1952, p. 29: Cecil Roth, Dublin Review, 191 (1932), 221; Asensio, art. cit., pp. 67-69; María Rosa lida [De MalkifL], RFH, 3 (1941), 150-154, descubrió el origen judío de Mena. Para Hernando del Pulgar, cf. J. DE M. Carriazo, est. prel. de su ed. de la Crónica de los Reyes Católicos, Madrid, 1943. Véase también M. SERRano Y SANz, "El linaje hebraico de La Caballería", $B A H, 73$ (1918), 161; J. Simón Dfaz, "El judaísmo de mosén Diego de Valera", RevBN, 6 (1945); F. Rodrígurz Marf́n, "Documentos hasta ahora inéditos referentes a Mateo Alemán (1546-16o7)", $B A E, 20$ (1933), 168 169 y 216 ("descendiente bautizado de judios por las ramas paterna y materna"); S. DF Madariaga, "Jews, christians and conversos", en su Christopher Columbus, London, 1939 [hay trad. española], cap. 6 (Colón), 11 (Deza, Talavera, Espina, Santa Fe, Vives, etc.) y 14, n. 10 (Torquemada), y en Spain and the Jews, London, 1946, pp. 20-28. En cambio, ya no se considera de origen judaico a Alfonso de Baena (cf. Y. MaLkiel en $H R, 18,195^{\circ}$, p. 337). 
fía y las ciencias. España pudo haber sido también la cuna del más grande filósofo de la raza, Baruch Spinoza, cuyo padre, llamado Miguel de Espinosa, nació en Portugal, descendiente, según se cree, de una familia de Espinosa, pueblo de la provincia de León o de Burgos.

Se sabe que estas personas distinguidas en la religión y en las letras tuvieron antecesores judíos; pero se ignora hasta qué punto su sangre era hebrea pura o mezclada. De alguno, como Melchor Cano, consta que era mezclada, y suponemos que la de otros lo fuera también. De todos modos, la mayor parte de ellos eran ya cristianos y desarrollaron sus aptitudes en la vida religiosa y literaria de la España católica.

Los conversos se infiltraron en la vida social por todos los resquicios que se les presentaban. Por sus matrimonios con católicos, su sangre se mezclaba en partes iguales al comienzo, y más adelante, en una proporción que gradualmente disminuía la que procedía de los ascendientes hebreos y acrecentaba la nueva inyectada por los cristianos. A la cuarta generación, ya se la declaraba "sangre limpia". Después de varios siglos la sangre israelita quedaría reducida a una proporción mínima. Serrano y Sanz, a quien no se puede tachar de tendencioso, calcula que hoy día existe en España más de un millón de individuos con algunas gotas de sangre judía en las venas, "que descienden de los hebreos convertidos al cristianismo en la Edad Media, sobre todo en los últimos años del siglo XIv y los primeros del Xv" (BAH, 73, 1918, 184).

Fernán Pérez de Guzmán"3 escribía en 1460: "yo he conoscido e conosco dellos [conversos] algunos buenos religiosos que pasan... áspera e fuerte vida de su propia voluntad... ansý en monesterios como en reformación de algunas órdenes". Según el libro del Alboraique (hacia $\left.{ }^{1488}\right)^{4.4}$, los conversos de Castilla la Vieja, León y Zamora eran sinceros: "apenas se fallarán dellos ningunos herejes". "Hay [en los siglos XIV-XVI] en el episcopado, en el clero, en las órdenes monásticas lo mismo que en la nobleza, gran número de descendientes de judíos que profesan el catolicismo con entera sinceridad" (BAtalllon, op. cit., t. 1, p. 71). Eugenio Asensio, al analizar el papel de los conversos dentro de la religiosidad española, aduce "el fervor con que los conversos se abalanzaron a la vida conventual" (art. cit., p. 59). "De parte de muchos hubo sincera reconciliación" (BENARdeTE, p. 28).

Uno de los muchos ejemplos que hemos citado y, sin duda alguna, el más notable de todos, es el de Santa Teresa de Jesús y su numerosa familia. Se habrá observado la religiosidad de toda ella, el número de familiares que, dotados de vocación y fe, siguieron el ejemplo de la Santa y se ofrendaron al servicio de la Iglesia católica. Por otra parte, son de advertir las abundantes alianzas entre los demás miembros de la familia de Teresa y miembros de familias de rancia estirpe cristiana. Se realizaba así la amalgama de ambos linajes. Existía compatibilidad entre las dos razas, no incompatibilidad racial, como alguien, desconocedor de los hechos históricos, ha escrito recientemente en España. Finaliza Alonso Cortés su trabajo en los siguientes términos: "Los

${ }^{43}$ Generaciones y semblanzas, ed. de J. Dominguez Bordona, Clas. cast. Madrid, 1924, p. 94. Cita de Castro, Aspectos, p. 106, n. 103.

44 I. LOFB, REJ, 18 (1889), 241, citado por CASTRO, Esp. en su hist., p. 473, n. 1. 
datos referentes a Juan de Toledo, abuelo de la Santa, responden a un formulario usual, y no deben causar sorpresa, por lo frecuente del caso, ni mucho menos conturbación. Precisamente ellos patentizan, con diáfana elocuencia, hasta qué punto en los inescrutables designios divinos, la gloriosa Santa de Ávila era una elegida".

El hecho de que ese mismo Juan Sánchez de Toledo, converso reconciliado, abuelo de Teresa, hubiera tomado como cónyuge a una cristiana, Inés de Cepeda, nos lleva a deducir que sus hijos poseerían sangre mezclada en partes iguales, es decir, en una proporción del cincuenta por ciento. Si a ello se añade que estos hijos, entre los cuales se contaba el futuro padre de la Santa, contrajeron enlaces matrimoniales con hijas y parientas de regidores de la ciudad de Ávila, cristianos viejos, de "limpia sangre", la proporción de la de sus vástagos, y por lo tanto la de Santa Teresa, sería equivalente a un setenta y cinco por ciento de cristiana y un veinticinco por ciento de judía. Santa Teresa se educó en la fe católica, sintió ardiente vocación y poseyó el genio que la elevó a la cúspide de la reforma religiosa y de la literatura mística.

\section{APÉNDICE}

Escrito este artículo, llega a nuestras manos la nueva biografía de Santa Teresa por el P. Efrén. Después de su lectura tenemos que rechazar las censuras del P. Ferreol y de J. M. Mohedano de que nos hicimos eco, excepto la que califica de error del P. Efrén el creer que Santa Teresa nació en Gotarrendura (pp. 211-212), en vez de en Ávila ${ }^{45}$. $Y$ rechazamos las críticas porque la nueva biografía, en lo que toca a los antecedentes genealógicos de la Santa, se basa en los documentos publicados por Alonso Contés, en el Espicilegio historial... de la Reforma, en esta $N$. Primitiva Provincia de Castilla la Vieja ${ }^{46}$, por fray Manuel de Santa María (ms. 8713 de la B. N. M.), no tenido en cuenta, que sepamos, antes de ahora, y en otros documentos ya conocidos, citados por nosotros, en especial el "pleito de herencia" de 1544 .

No obstante, el P. Efrén deduce algunas interpretaciones y conclusiones que son una vuelta por pasiva de la documentación citada. Asegura que Juan Sánchez, abuelo de la Santa, pertenecía a una hacendada familia de mercaderes cristianos de Toledo, que apostató de su religión y se convirtió al judásmo, mas luego se reconcilió y confesó y fue penitenciado por la Inquisición con un sambenitillo con sus cruces. Es decir que el P. Efrén entiende algunos de los documentos al revés. Harto claros son, sin embargo. La comunidad de Ávila alegaba "que los hijos

t5 El P. Ferreol, en sus invectivas contra el P. Efrén, le acusa al final, con notodia ligereza, de haber terminado la biografía de la Santa con un corte arbitrario. Si hubicra leido la solapa posterior de la cubierta del volumen, se habría enterado de que la biografía tiene una segunda parte, que se publicará en un próximo tomo.

1: Sobre este Espicilegio, véase el P. Errén, p. 160, n. 3. En cuanto al pleito de hidalguía, parece que el P. Efrén dio con él guiado por "el catálogo impreso de la Chancillería [de Valladolid], donde sin pretenderlo topamos con su referencia" (p. 169 , n. ı; y véase supra, nuestra nota 2). Sin embargo, reconoce allí mismo haber visto los extractos publicados por Alonso Cortés. 
de Juan Sánchez de Toledo, nacidos en Toledo, son conversos $e$ descienden de linaje de judios por parte de su padre e abuelo" (Alonso Cortés, p. 91). Por otra parte, no se daba el caso, o por lo menos era rarísimo, de que un cristiano se convirtiera al judaísmo ${ }^{47}$, y era también raro encontrar un mercader que no perteneciera a la raza hebraica. Más adelante afirma el $\mathrm{P}$. Efrén que "los datos históricos son más que suficientes para demostrar el linaje hidalgo de Santa Teresa" (p. 161). En efecto, la sentencia del pleito de hidalguía fue favorable. En resolución, el P. Efrén, historiador respetuoso, al fin y al cabo, de los documentos, se ve obligado a confesar que la Santa pertenecía a otro u otros linajes. Vamos a copiar sus propias palabras:

Los testigos que declaran en los procesos de canonización dicen unánimes que Santa Teresa era hija de "caballeros nobles hijosdalgos". Tras este señuelo, cargados de fantasías, se dieron los primeros biógrafos a buscar sus orígenes en la más rancia prosapia. Era mal de la época. El horror a tener cruce de sangre con moros o judíos hacía sentir la necesidad de comprobar la propia "limpieza", pues había llegado a tales términos la prevención que sin ella no se podían ejercer oficios honorables... De ahí el "honor de la sangre" que obligaba a defenderse con largas genealogías que arraigaran en los fundadores de la patria. Santa Teresa tuvo en mucho, como todos, ser nacida de padres hidalgos; descle niña oiría en su casa interminables ponderaciones de su noble alcurnia. En su edad madura no pensaba tanto; pero seguían pensando, y mucho, los que la estimaban. Uno de éstos era el ingenuo P. Gracián, de cuyas pesquisas cnterada la Santa díjole un día con enojo "que le bastaba scr hija de la Iglcsia Católica" ${ }^{48}$.

Otro testimonio, observado asimismo por nosotros, recoge del pleito de hidalguía citado, en el que los litigantes "eran acusados de que se llamaban Cepeda por abolengo de su madre" (p. 164, n. உo), y de él infiere el P. Efrén que "si, como parece, el apellido Ahumada, y aun quizás el de Cepeda, sólo son teresianos por la rama femenina, su linaje quedaría como diluído entre muchos, adquiriendo con ello cierta universalidad, de suerte que Santa Teresa no sería, de fijo, posesión exclusiva de un solo linaje, sino de muchos sin número, y así muchos linajes podrían verse enlazados con esta Santa singular, hija y madre a la vez de toda España" (p. 164).

Tales son los términos textuales del P. Efrén, fraile carmelita descalzo, estampados en un libro aprobado por el General de la Orden, fray Silverio de Santa Teresa, y por el Provincial de Aragón-Valencia, con el nihil obstat del Censor y el imprimatur del Obispo auxiliar y Vicario general de Madrid. A más de ello, fue editado en la Biblioteca

47 Menf́ndez Pelayo registra uno solo en su detallada Historia de los heterodoxos (libro V, cap. 2) y lo llama "peregrino caso": el de don Lope de Vera y Alarcón, caballero vallisoletano, cristiano vicjo, que se convirtió al judaismo y fue quemado vivo por la Inquisición en un auto de fe (Valladolid, 1649) al que se dio gran importancia, aparato y publicidad por toda España para ejemplaridad, ya que se trataba de un hecho excepcional. Por otra parte, a este don Lope no se le llamó "converso", sino "judaizante".

${ }^{48}$ Véase supra, p. 377. El P. Efrén registra en nota (p. 160) el lugar en que sc halla este testimonio: J. Gracián, Espiritu de la B. Ana de San Bartolomé, diál. I (Bibl. Míst. Carmelitana, t. 17 , p. 259). 
de Autores Cristianos, bajo los auspicios y la alta dirección de la Pontificia Universidad de Salamanca.

También hemos leído, después de terminado nuestro artículo, una breve nota del profesor Francisco Cantera, en Sef, 13 (1953), 402-404, acerca de la Vida de la Santa por el P. Efrén. Cantera encabeza su reseña con un título que es una pregunta: “Santa Teresa de Jesús de ascentencia judía?" Califica la nueva biografía (que él llama "bibliografia" por errata o descuido) de "trabajada y jugosa"; señala "las múltiples páginas que se refieren a judíos, ya a los hebreos y los conversos en general..., ya especialmente a los judíos avileses y su barrio", y hace constar que "ofrecen particular interés los datos referentes al abuelo de Santa Teresa, Juan Sánchez". No habla de los documentos impresos por Alonso Cortés. Se basa únicamente en la revesada conclusión del P. Efrén y añade: "Esto es lo que hay de probado en la Biografía de la Santa avilesa sobre su asendereada ascendencia hebrea, de que no todos hablan con acierto" (p. 403). Ya hemos visto que los documentos históricos prueban lo contrario, hasta el extremo de que el propio P. Efrén reconoce, como hemos copiado, que la Santa poseía varios linajes. Con ello, por lo visto, no está de acuerdo Cantera, como tampoco con la siguiente manifestación del $\mathrm{P}$. Efrén. Alega éste que en los escritos de Santa Teresa se deja sentir "un sabor agustiniano y semítico". A lo que contesta Cantera: "A juicio nuestro debe descartarse por completo que rezumen el menor sabor semítico". Y agrega: "Sinceramente estimamos que en ésta, como en buena parte de las notas de carácter lingüístico que lleva el Libro de la vida, la labor de los anotadores deja que desear y se halla falta de total acierto" (pp. 403-404).

Con posterioridad a la reseña de Cantera apareció la $2^{a}$ edición, aumentada, de la obra de Castro tantas veces citada, con el nuevo título de La realidad histórica de España (México, 1954), y en ella da cuenta el autor del hallazgo de Alonso Cortés, dedicándole la p. 539. Castro interpreta así los documentos: "Hechas averiguaciones quedó probado que el padre de los Cepeda, Juan Sánchez, habiendo sido penitenciado por la Inquisición de Toledo en 1458, como confeso que había recaído en su anterior judaísmo. .., fue condenado", etc. "El abuelo de Santa Teresa, y sus hijos más tarde, eran ricos comerciantes, arrendadores de rentas reales, diezmos, etc.; hacían, en suma, lo mismo que los judíos habían venido haciendo antes de hacerse o llamarse cristianos... Lo evidente, en todo caso, es que Santa Teresa ha de considerarse como otra gran figura inclusa en la línea cristiano-oriental. Su especial autobiografismo me había hecho pensar en conexiones islámicas o judaicas" ${ }^{49}$. Volviendo a los documentos de Alonso Cortés, se

49 En cfecto, en España en su historia, desconocedor todavía Castro del pleito de la familia Cepeda, ya presentía cl semitismo de Santa Teresa. Al analizar la obra de la monja Teresa de Cartagena, encuentra analogías con la Vida de Santa Teresa, apartadas ambas por casi un siglo. "De aquélla piensan algunos -dice- que era descendiente de Pablo de Santa María, es decir de un judio converso; pero carezco de medios para aceptarlo o rechazarlo... Lo cierto es que maravilla encontrax en el siglo xv una confesión íntima, con conciencia y análisis del yo más intimo, de mi yo. De aquí a Santa Teresa no hay sino un paso" (pp. 324-325, n. 2). Véanse también sus Aspectos del vivir hispánico, p. 156, n. 133 . 
detiene Castro en lo que toca al afán de limpieza de sangre y al ansia de obtener la hidalguía por los cristianos nuevos (léanse las pp. 497, 500 y 543 ). Entresacamos, y con esto terminamos, la siguiente declaración (p. 504, n. 135), que no figura en la primera edición: "Hablando rigurosamente, los conversos de la segunda generación en adelante no eran judíos; habría que incluirlos en una especial categoría humana centrada justamente en su voluntad de no querer ser judíos, y de exceder en ortodoxia a los cristianos viejos". Por una razón análoga había afirmado Benardete (op. cit., p. 3o, y carta) que en el siglo xvi ya no había judíos en España: "Una centuria de vida como conversos transformó un subido tanto por ciento de ellos..., los cuales... se incorporaron completamente, por sí mismos, en el seno de la nación española, borrando así toda huella de su origen... y pronto se conducian como hidalgos".

En conclusión, el P. Efrén, comprensivo unas veces y vacilante otras, empeora la cuestión de la hidalguía con la hipótesis de que el abuelo de la Santa no fue judío converso, sino un cristiano apóstata, caso, como hemos dicho, casi monstruoso. La actitud del profesor Cantera, contrario al semitismo de la monja de Ávila, se manifiesta en meras aseveraciones terminantes sin testimonios que las apoyen. En cambio, Castro toma por fundamento los datos publicados por Alonso Cortés. Nosotros igualmente nos hemos ajustado a los documentos en nuestro artículo.

Homero Serís

Centro de Estudios Hispánicos, Syracuse University, New York. 